
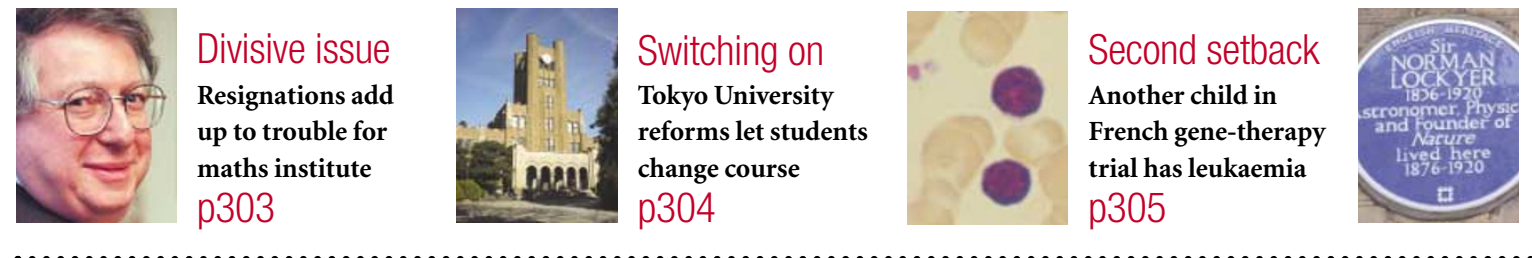

\title{
Landmark
}

Nature's founder honoured by heritage body p307

\section{Failed mission launch prompts ESA to reconsider comet target}

\section{Declan Butler, Paris}

STUNNING SPACECRAFT SEEKS COMET. Should be small and highly active, and reachable by launch from Earth within the next 2.5 years. Rendezvous must require no major engineering works, and incur few additional costs. Technically risky options need not apply.

Europe's comet scientists are this week struggling to determine a new route - and probably a new target - for Rosetta, the world's largest and most ambitious comet mission, whose postponed launch last week saw it miss the January window that would have allowed the probe to land on the comet Wirtanen in 2010 (see Nature 421, 198; 2003).

The scientists now face a formidable challenge if they are to realize Rosetta's exacting goals. The truck-sized craft must be lobbed into the outer reaches of the Solar System, and accelerated to the 9 kilometres per second needed to catch up with its tiny target, a dirty snowball barely a few kilometres across. The probe then has to orbit the comet, plant a lander on it, and hang on while the comet arcs around the Sun.

The sooner Rosetta is launched, the less the postponement will cost the European Space Agency (ESA) - most costs are derived from retaining the design and development teams until the launch. But most of the earliest launch possibilities for Rosetta carry major technical risks.

Two dates later this year would use Venus, instead of Mars, to provide a gravitational 'catapult' that would enable Rosetta to catch up with its original target, Wirtanen. But these options are unlikely to be selected, according to Gerhard Schwehm, who leads the core Rosetta project team from ESA's European Space Research and Technology Centre (ESTEC) in Noordwijk, the Netherlands. The probe was designed for cold space, rather than the cauldron of the inner Solar System. "The heat load is too high for some of the spacecraft's subsystems to survive," he says. David Southwood, ESA's director of science agrees: "You can't just install a fan," he quips.

A January 2004 launch window, on the other hand, would retain both the Mars pass and the 2010 Wirtanen rendezvous. This particular flight plan would call for a rocket launch velocity that is higher than previously planned, however. That would leave mission planners facing the unenticing prospect of using the Ariane 5 'heavy lifter' that blew up in December - the incident that created the problem in the first place. Schwehm prefers to stick with the original launcher, especially as there is no guarantee that the souped-up model will be flying safely by January 2004.

That leaves scientists with what might be their best bet: shooting for another comet from the Jupiter family, so called because its members' orbits cross that of Jupiter and are influenced by the planet's gravitational pull. The likely target will be in a phase and orbit where it is producing a lot of hot gas and dust, says Schwehm.

This will involves reviewing reams of existing observations, and making new ones. Problems with the various options include

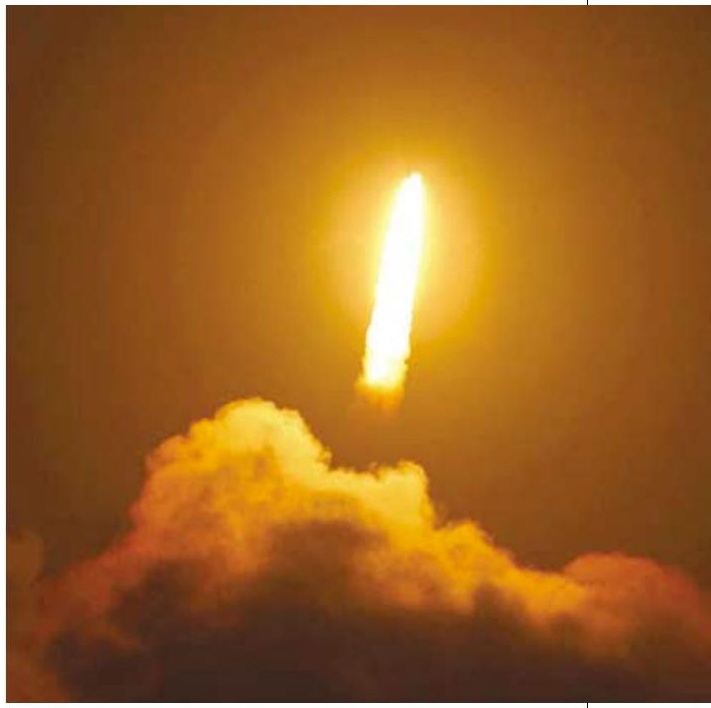

An explosion of the Ariane launcher caused the Rosetta comet probe to miss its launch window.

\section{Report backs military axis on space}

\section{Declan Butler, Paris}

Europe should consider a sweeping reorganization of its space programme to integrate its civilian and military endeavours, argues a French report released last Friday.

If approved, the reorganization would be the largest since the European Space Agency (ESA) was founded in 1975.

The report, from a commission headed by Roger-Maurice Bonnet, who led ESA science for a decade before retiring in 2001, speaks of a "major crisis" in European space policy. It calls for the revival by 2005 of a high-level European Space Conference to spearhead the programme's revival.

Contentiously, the report also says that the programme should be led by military requirements - albeit while embracing the interests of science, agriculture, navigation, telecommunications, environment and technology development. The United States spends six times more than Europe on its space programmes, it notes.
"We think that the major effort of the United States in military space is a lesson for Europe," says Bonnet, adding that the transformation of ESA into a joint military-civilian agency is only one possible route to building a stronger programme. The report also advocates government intervention to consolidate Europe's fragmented aerospace and defence industries.

The French government is likely to back the report when it responds to it in March but some other governments, less taken by the idea of competing with the United States in this sphere, may not be so enthusiastic.

Nevertheless, the explosion of the Ariane $V$ rocket late last year points to the need for reform. Arianespace, the rocket's maker, is struggling to remain profitable. France's national space agency, the CNES, the largest in Europe, is in a budgetary crisis, and other national space programmes are stagnant or in decline. 
possible design changes needed to the probe, and how the size and surface of the target comet will affect the lander's descent plan.

Rosetta's planners currently seem to favour a spring 2004 launch that would allow targeting of the comet ChuryumovGerasimenko; other possible windows would allow visits to the comets Howell, Finlay, Schwassmann-Wachmann 2 and Wild-2. Launch dates for these options cannot be firmly defined until scientists at ESA's Operations Centre in Darmstadt, Germany, take ESTEC's proposals and work out the various possible trajectories to get the craft to its potential targets. But these targets might not be reachable until 2015 - a painful delay for those involved in a mission for which planning began in 1993.

Rosetta teams will meet on 13 February to consider possible solutions to the problem, before presenting them to ESA's Science Programme Committee on 26 February. But the crunch will come in May, when ESA will select one of the options - and decide how to pay for it. Southwood estimates that the delay will inflate the mission's E1-billion (US\$1-billion) price tag by a further E50 million-100 million.

ESA may ask its member states to make a one-off contribution to cover this, although with national space budgets under pressure, this may not be forthcoming (see previous page). That could force the agency to make cuts elsewhere in its science programme - possibly including the cancellation of Venus Express, ESA's planned 2005 mission to Venus.

\section{Mozambique prime minister tipped for global health post}

\section{Declan Butler, Paris}

An African official is emerging as the frontrunner to succeed Gro Harlem Brundtland as director-general of the World Health Organization (WHO) in May.

If he is elected, Mozambique's prime minister Pascoal Mocumbi will be the first African to head the WHO. The chances that Mocumbi will win a secret ballot of the WHO's 32-strong executive board to be held next week increased after his strongest African rival, former Senegalese health minister Awa Marie Coll-Seck, withdrew from the contest. Mocumbi says that he would resign from his current position if appointed to lead the Geneva-based organization.

Others shortlisted are Julio Frenk Mora, Mexico's health minister; Peter Piot, a former AIDS researcher who now heads the Joint UN Programme on HIV/AIDS (UNAIDS); Jong Wook Lee, a physician from South Korea, who heads the WHO's tuberculosis programme; and former Egyptian health minister Ismail Sallam. The World Health Assembly is expected to endorse the board's choice when it meets in Geneva in May.

The WHO is under strong pressure to end the political horse-trading that traditionally characterizes its elections. This time, The Lancet and the New York-based Rockefeller Foundation have organized a campaign to introduce greater openness into what they describe as the "secret and generally unaccountable process" of the election.

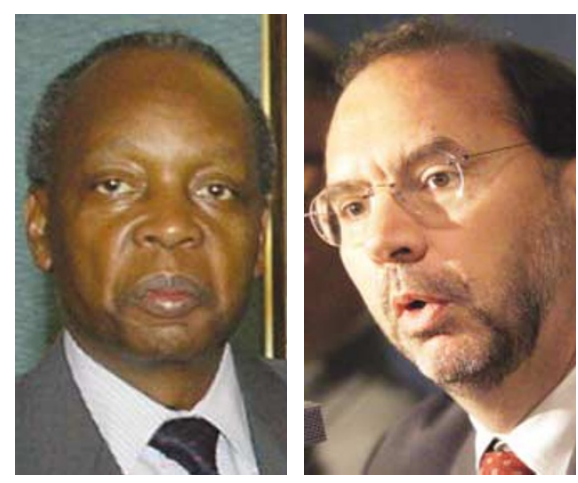

Pascoal Mocumbi (left) and Peter Piot are in the running to head the World Health Organization.

Critics of the election process say that it reflects the highly politicized workings of many international agencies during the cold war, and should be replaced by a more open and merit-based contest when the next director-general is elected in 2008.

Under pressure to fight an open campaign, candidates initially agreed to take part in a two-hour question-and-answer session on 19 January, set up by non-governmental organizations and the Interactive Health Network's World Health Channel, and broadcast live on the Internet. But several of the candidates pulled out of the session.

Each candidate has, however, taken up The Lancet's challenge to provide detailed responses on its website to ten questions about the WHO's future direction.

\section{Bushfires annihilate Australian observatory}

Carina Dennis, Sydney

One of Australia's premier observatories has been destroyed by bushfires that have raged for days in and around the nation's capital, Canberra. Flames engulfed Mount Stromlo

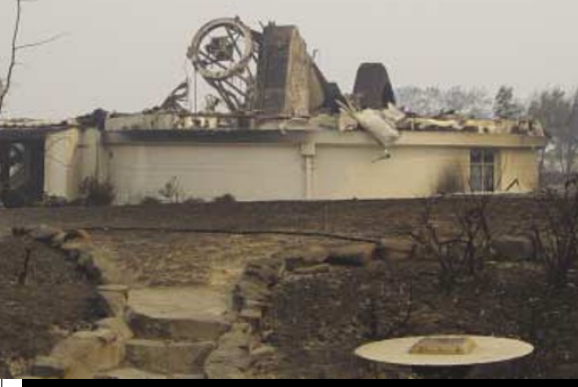

Gutted: the charred remains of Mount Stromlo Observatory - remarkably, some data survived.
Observatory, which lies at the western outskirts of the city, on 18 January, melting telescope housings, incinerating workshops and destroying precious archives.

"It looks like it has been firebombed," says Brian Schmidt, a research fellow at the Australian National University's astronomy school in Canberra, which operates the observatory. "All our active telescopes have been destroyed."

No astronomers were killed or injured in the fires - which caused four deaths and injured hundreds in the area - but several of their homes near the observatory were destroyed. Preliminary estimates value the observatory's losses at more than $\mathrm{A} \$ 20$ million (US\$12 million), although Schmidt thinks the final figure could be twice as much.

Many research projects have been cut short or temporarily halted by the fire, including a five-year programme led by
Schmidt to digitally map the southern sky.

The observatory's construction workshops were destroyed in the blaze, including those that were to be used for a A \$6.3-million contract to build an imager for the Gemini South Telescope in Chile. A A \$5-million near-infrared integral field spectrograph for the Gemini North Telescope in Hawaii, which was ready for shipment, was also damaged.

Historical records have been lost, including drawings of astronomical objects, some dating from the nineteenth century. But buildings containing computers and databases were spared. "Our current research data seem to be intact," says Schmidt.

The Australian National University has already given assurances that the observatory will be rebuilt, with resources and facilities made available to researchers to fulfil equipment contracts in the interim. 